\title{
Fatal Anaphylactic Sting Reaction in a Patient with Mastocytosis
}

\author{
N. Wagner ${ }^{a} \quad$ D. Fritze ${ }^{b} \quad$ B. Przybillac ${ }^{c}$ M. Hagedorn ${ }^{a} \quad$ F. Ruëffc

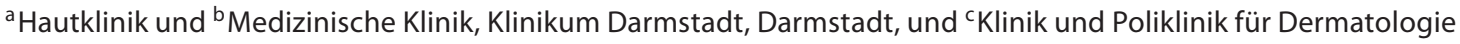 \\ und Allergologie, Ludwig-Maximilians-Universität, München, Deutschland
}

\section{Key Words}

Anaphylaxis, fatal $\cdot$ Mastocytosis $\cdot$ Hymenoptera venom allergy $\cdot$ Serum tryptase

\begin{abstract}
We report on a 33-year-old female patient with indolent systemic mastocytosis and urticaria pigmentosa who died of an anaphylactic reaction after a yellow jacket sting. As she had no history of previous anaphylactic sting reaction, there was no testing performed in order to detect hymenoptera venom sensitization. But even if a sensitization had been diagnosed, no venom immunotherapy (VIT) would have been recommended. It is almost certain that VIT would have saved her life and it is most likely that VIT is indicated in some patients with mastocytosis with no history of anaphylactic sting reaction. However, no criteria have been established in order to allow a selection of mastocytosis patients eligible for such a 'prophylactic' VIT. C Copyright $\odot 2008$ S. Karger AG, Basel
\end{abstract}

Patients with mastocytosis and hymenoptera venom allergy (HVA) represent a particular risk group for very severe anaphylactic sting reactions [1-3]. Several fatal sting reactions have been reported in such patients $[4,5]$. Nevertheless, it is still controversial whether patients with mastocytosis and HVA should receive venom immunotherapy (VIT) or not. Some authors believe that anaphylactic reactions in patients with mastocytosis are generally of a pseudoallergic nature [6]. In this case VIT would not be helpful. Individual reports suggest more side effects during VIT in patients with mastocytosis [1]. On the other hand, there is evidence from other studies that VIT may be safe and effective in the vast majority of patients with mastocytosis $[2,7]$.

Here we present a fatal sting reaction in a female patient with systemic mastocytosis. Our patient had noticed red macules at the proximal upper legs and at the trunk during her second pregnancy when she was 29 years old. About 3 years later she presented to our outpatient clinic. She also had a history of asthma, which had resolved and did not require medical treatment. Otherwise she was healthy, and she had no history of previous anaphylaxis.

Skin examination revealed multiple dark red-brownish macules of about $0.5 \mathrm{~cm}$ diameter which were erective upon rubbing (Darier's sign). Histological examination showed mast cell infiltration in the upper dermis. Routine laboratory parameters were without pathological findings. Baseline serum tryptase concentration was increased to $57 \mu \mathrm{g} / \mathrm{l}$ (95th percentile $11.4 \mu \mathrm{g} / \mathrm{l}$ ). Bone marrow biopsy showed spindle-shaped mast cells with expression of CD117. Abdominal sonography, gastroscopy, and colonoscopy were without pathological findings.

\section{KARGER \\ Fax +4161306 1234 E-Mail karger@karger.ch} www.karger.com (c) 2008 S. Karger AG, Basel

$1018-2438 / 08 / 1462-0162 \$ 24.50 / 0$

Accessible online at:

www.karger.com/iaa
Correspondence to: Dr. Nicola Wagner

Hautklinik, Klinikum Darmstadt

Heidelberger Landstrasse 379, DE-64297 Darmstadt (Germany)

Tel. +496151 107 4112, Fax +496151 1074199

E-Mail Nicola.Wagner@klinikum-darmstadt.de 
Our diagnosis was an indolent systemic mastocytosis with urticaria pigmentosa. There was no indication for specific treatment. We prescribed an emergency kit, composed of antihistamine drops, corticosteroid fluid, and an epinephrine autoinjector, and instructed the patient to carry it with her all the time and to use it in case of anaphylactic symptoms. As she had no history of anaphylactic sting reactions, no further diagnostics were done.

One year later, when she was 33 , the patient was stung into the neck by a yellow jacket. At that time, she did not carry her emergency kit with her. Initially she complained about tachycardia. Within a few minutes she collapsed, lost consciousness and gasped for about $10 \mathrm{~min}$. When the emergency physician arrived, her blood pressure was undetectable, and the patient was deeply comatose. She was immediately intubated, and cardiopulmonary resuscitation was started. Emergency therapy was successful and after hemodynamic stabilization the patient was transferred to an intensive care unit. Subsequently, however, she did not regain consciousness. Four days later she died of hypoxic brain damage which could be confirmed at autopsy.
VIT is a highly effective measure to prevent anaphylaxis to hymenoptera stings. In our patient there was no history of a prior anaphylactic sting reaction. Therefore, we did not perform tests to detect venom sensitization. But even if we had done so and had detected venom sensitization, we would not have recommended VIT to her. As anaphylaxis is frequent in patients with mastocytosis it is part of our clinical routine to provide these patients with an emergency kit. Our patient did not carry her emergency kit with her when she was stung. It cannot be determined whether its use would have altered the outcome. However, it is almost certain that prophylactic VIT would have saved the life of this individual patient. It is highly likely that VIT is indicated in some patients with mastocytosis even if there has been no preceding anaphylactic sting reaction. The rationale for such an individual indication can be found in the striking coincidence of mastocytosis and HVA. However, thus far, there are not yet any established criteria which would allow the identification of patients possibly eligible for such a 'prophylactic' VIT.

\section{References}

1 Dubois AE: Mastocytosis and hymenoptera allergy. Curr Opin Allergy Clin Immunol 2004;4:291-295.

2 Ruëff F, Placzek M, Przybilla B: Mastocytosis and hymenoptera venom allergy. Curr Opin Allergy Clin Immunol 2006;6:284-288.

3 Ludolph-Hauser D, Ruëff F, Fries C, Schöpf P, Przybilla B: Constitutionally raised serum concentrations of mast-cell tryptase and severe anaphylactic reactions to hymenoptera stings. Lancet 2001;357:361-362.
4 Oude Elberink JNG, de Monchy JGR, Kors JW, van Doormaal JJ, Dubois AEJ: Fatal anaphylaxis after a yellow jacket sting, despite venom immunotherapy, in two patients with mastocytosis. J Allergy Clin Immunol 1997; 99:153-154.

5 Reimers A, Müller U: Fatal outcome of a Vespula sting in a patient with mastocytosis after specific immunotherapy with honey bee venom. Allergy Clin Immunol Int J WAO Org 2005;17(suppl 1):69-70.
6 Florian S, Krauth MT, Simonitsch-Klupp I, Sperr WR, Fritsche-Polanz R, Sonneck K, Fodinger M, Agis H, Bohm A, Wimazal F, Horny HP, Valent P: Indolent systemic mastocytosis with elevated serum tryptase, absence of skin lesions, and recurrent severe anaphylactoid episodes. Int Arch Allergy Immunol 2005;136:273-280.

7 Fricker M, Helbling A, Schwartz L, Müller U: Hymenoptera sting anaphylaxis and urticaria pigmentosa: clinical findings and results of venom immunotherapy in ten patients. J Allergy Clin Immunol 1997;100:11-15. 